

\title{
Effect of carbohydrate sugars as a capping agent on the size and morphology of pure
}

\section{$\mathrm{Zn}_{2} \mathrm{SnO}_{4}$ nanostructures and their optical properties}

\author{
Maryam Masjedi-Arani, Masoud Salavati-Niasari* \\ Institute of Nano Science and Nano Technology, University of Kashan, P.O. Box 87317-51167, Kashan, Islamic \\ Republic of Iran \\ *Corresponding author: Tel.: +98 315591 2383, Fax: +98 3155913201. \\ E-mail address: Salavati@kashanu.ac.ir
}

\begin{abstract}
Pure $\mathrm{Zn}_{2} \mathrm{SnO}_{4}$ nanostructures were prepared via simple and rapid co-precipitation approach in presence of different carbohydrate sugars as a green capping agents. The effect of different carbohydrate sugars such as glucose, sucrose and starch on the size, morphology and optical properties of $\mathrm{Zn}_{2} \mathrm{SnO}_{4}$ nanostructures were investigated. The results demonstrated that applying the appropriate amount of sugars could be effective in particle size, morphology and optical properties control.
\end{abstract}

Keywords: Nanoparticles; Semiconductor; Electron microscopy; Optical properties

\section{Introduction}

Zinc stannate $\left(\mathrm{Zn}_{2} \mathrm{SnO}_{4}\right)$ as a ternary semiconductor is widely used in applications such as dye-sensitized solar cells [1], photocatalysis [2], lithium ion batteries [3] and gas sensing systems [4]. $\mathrm{Zn}_{2} \mathrm{SnO}_{4}$ has a wide band gap of $3.6 \mathrm{eV}$ with excellent optical properties, great chemical sensitivity and low visible absorption. Different possible routes have been proposed for preparing nanocrystalline $\mathrm{Zn}_{2} \mathrm{SnO}_{4}$ including hydrothermal [5], co-precipitation [6], microwave-assisted hydrothermal [2], solid state calcinations [8] and thermal evaporation [9]. Among of these methods, co-precipitation is simple, rapid, cost effective approach, potential for large-scale production and simply control the shape and particle size for preparing of $\mathrm{Zn}_{2} \mathrm{SnO}_{4}$ nanostructures. For size and morphology 

properties is choosing appropriate carbohydrate sugar shell. This shell is a molecular monolayer encapsulating the core. The carbohydrate sugar perform the task of adsorbent and stabilizer. The $\mathrm{Zn}_{2} \mathrm{SnO}_{4}$ surfaces are occupied by hydroxy groups. The carbonyl and hydroxyl groups of sugars will form hydrogen bonds with hydroxyls of $\mathrm{Zn}_{2} \mathrm{SnO}_{4}$ surface. As the capping agent molecules have many carbonyl and hydroxyl groups and $\mathrm{Zn}_{2} \mathrm{SnO}_{4}$ has many hydroxy groups on the surface, sugar molecules will entwine the $\mathrm{Zn}_{2} \mathrm{SnO}_{4}$ surface tightly. From these possible mechanism results, it can be concluded that probably a proper amount of sugar is attached to the surface of nanoparticles which may have an effective role in preventing nanoparticles agglomeration. In this way, these kind of capping agents have an advantageous role on controlling size, shape, and uniformity of final products. Beside the common surfactants, recently our team has focused on the effect of carbohydrate sugars as a capping agent on the properties of obtained products $[10,11]$. Moreover, Due to the environmental pollutions, the use of natural capping agent instead of chemical compounds has developed in the past decades $[12,13]$. For the first time, pure $\mathrm{Zn}_{2} \mathrm{SnO}_{4}$ nanostructures were prepared at the short time by using different sugars such as glucose, sucrose and starch with various steric hindrances as monosaccharide, disaccharide and polysaccharide, respectively. The effect of different carbohydrate sugars on the size, morphology and optical properties of $\mathrm{Zn}_{2} \mathrm{SnO}_{4}$ nanostructures were investigated. The results demonstrated that applying the appropriate amount of sugars could be effective in particle size, morphology and optical properties control.

\section{Experimental}

Materials and physical measurements: All the chemical reagents for the synthesis of $\mathrm{Zn}_{2} \mathrm{SnO}_{4}$ nanostructures such as $\mathrm{Zn}\left(\mathrm{NO}_{3}\right)_{2} .2 \mathrm{H}_{2} \mathrm{O}, \mathrm{SnCl}_{2} .2 \mathrm{H}_{2} \mathrm{O}$, glucose, sucrose, starch, $\mathrm{Na}_{2} \mathrm{CO}_{3}$ were commercially available and employed without further purification.). X-ray diffraction (XRD) patterns were recorded by a Philips-X'pertpro, X-ray diffractometer using Ni-filtered $\mathrm{Cu}$ K $\alpha$ radiation. GC-2550TG (Teif Gostar Faraz Company, Iran) were used for all chemical analyses. Scanning electron microscopy (SEM) images were obtained on LEO-1455VP equipped 


\section{Results and discussion}

XRD patterns of the products synthesized before and after calcination at $1000{ }^{\circ} \mathrm{C}$ are shown in Fig. $1 \mathrm{a}$ and b, respectively. The diffraction peaks observed in Fig. 1a and b can be indexed to pure cubic phase Zinc Tin Hydroxide (JCPDS card no. 73-2384) and cubic phase Zinc Tin Oxide (JCPDS card no. 24-1470), 
respectively. The crystallite size diameter (D) of the $\mathrm{Zn}_{2} \mathrm{SnO}_{4}$ product calculated by Debye-Scherrer equation [14] have been found to be $35.4 \mathrm{~nm}$ for sample No.2.

EDS spectrum of $\mathrm{Zn}_{2} \mathrm{SnO}_{4}$ nanoparticles (sample No. 2) is illustrated in Fig. 1c. The lines of $\mathrm{Zn}, \mathrm{Sn}$ and O are obviously observed.

To examine the role of the different carbohydrate sugars on the morphology and size of the products, $\mathrm{Zn}_{2} \mathrm{SnO}_{4}$ nanostructures were synthesized by monosaccharide, disaccharide and polysaccharide sugars. Fig. 2a-d show the SEM images of the $\mathrm{Zn}_{2} \mathrm{SnO}_{4}$ nanostructures synthesized in presence of glucose, sucrose, starch and without capping agent, respectively. These results show that using glucose and sucrose sugars lead to synthesis of $\mathrm{Zn}_{2} \mathrm{SnO}_{4}$ nanoparticles. However, by using starch sugar, nano plate products are obtained. By comparing SEM images of Fig. $2 \mathrm{a}$ and $b$, it can be seen that particle sizes of the $\mathrm{Zn}_{2} \mathrm{SnO}_{4}$ synthesized by sucrose are smaller than those produced by glucose due to higher steric hindrance effect of sucrose. The carbonyl and hydroxyl groups of sugars will form hydrogen bonds with hydroxyls of $\mathrm{Zn}_{2} \mathrm{SnO}_{4}$ surface. In this way, the sugars as a shell are adsorbed on the surface of $\mathrm{Zn}_{2} \mathrm{SnO}_{4}$ nanoparticles. Nano plate products were synthesized by using starch sugar, as starch sugar has a long chain of hydroxyl groups. But glucose and sucrose sugars with having less carbonyl and hydroxyl groups, synthesize nanoparticle products. To investigate the effect of the sugar on the morphology and size of the products, the blank test was carried out without using the sugar. According to the Fig. 2d, it can be seen that the morphology of the product is agglomerated and irregular. The corresponding TEM for samples No. 1-3 were synthesized in presence of glucose, sucrose and starch are shown in Fig. 2 e-g. As shown in Fig 2e-g, $\mathrm{Zn}_{2} \mathrm{SnO}_{4}$ products prepared in presence of glucose and sucrose are nanoparticles and in presence of starch are nanoplates. Fig. $2 \mathrm{~h}$, i show the HRTEM image and SAED pattern of $\mathrm{Zn}_{2} \mathrm{SnO}_{4}$ nanostructures prepared in presence of the sucrose sugar, respectively. Fig. $2 \mathrm{~h}$ shows representative HRTEM image of the specimen. In the HRTEM image, the distance between the two adjacent planes, $d$, is measured to be $0.34 \mathrm{~nm}$. Fig $2 \mathrm{i}$ shows the selected area 
electron diffraction (SEAD) pattern of $\mathrm{Zn}_{2} \mathrm{SnO}_{4}$ nanostructures. The ring-like SAED pattern indicates that the nanostructures are polycrystalline.
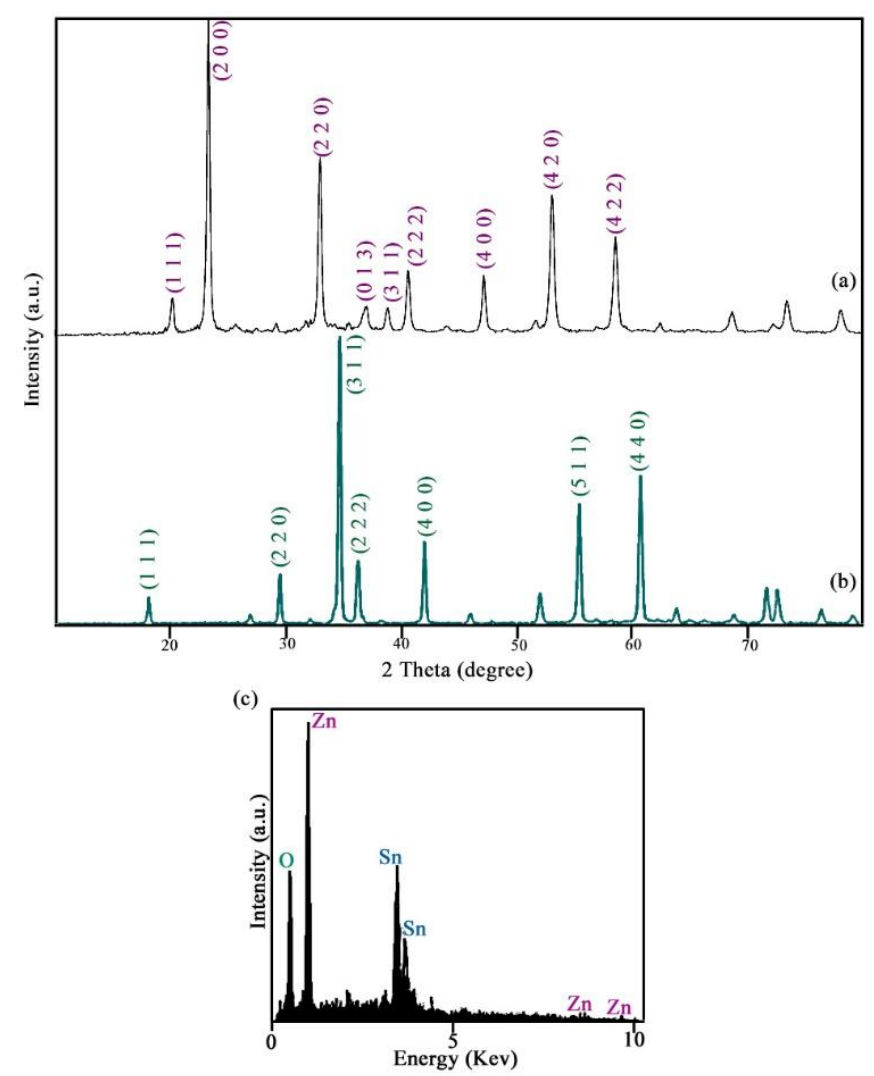

Fig. 1. XRD patterns of as-prepared products (a) before and (b) after calcination and (c) EDS pattern of the $\mathrm{Zn}_{2} \mathrm{SnO}_{4}$ nanoparticles (sample No. 2).

The UV-Vis Diffuse Reflectance spectroscopy of sample Nos. 2-4 are shown in Fig 3a-c. As shown in this figure, the position of absorption edges are various. In comparison to the blank product (Fig. 3c), the absorption edge of prepared sample by sucrose (Fig. 3a) shift to blue region. The fundamental absorption edge in most semiconductors follows the exponential law. Using the absorption data, the band gap was estimated by Tauc's relationship:

$$
\alpha=\frac{\alpha_{0}\left(h v-E_{g}\right)^{n}}{h v}
$$



gap of the material, and $n$ depends on the type of electronic transition and can be any value between $1 / 2$ and 3 [15]. The energy gaps of the samples have been determined by extrapolating the linear portion of the plots of $(\alpha \mathrm{h} v)^{1 / 2}$ against $\mathrm{h} v$ to the energy axis (Fig. 3d-f). The $\mathrm{E}_{\mathrm{g}}$ values are calculated 3.68, 3.6 and $3.62 \mathrm{eV}$ for the samples Nos. 2-4, respectively. By decreasing of particles size (sample No. 2 and 4), energy gap increased. The difference of band gap values of samples have been attributed to variations size and morphology of nanostructures and the type of electronic transition $[16,17]$.

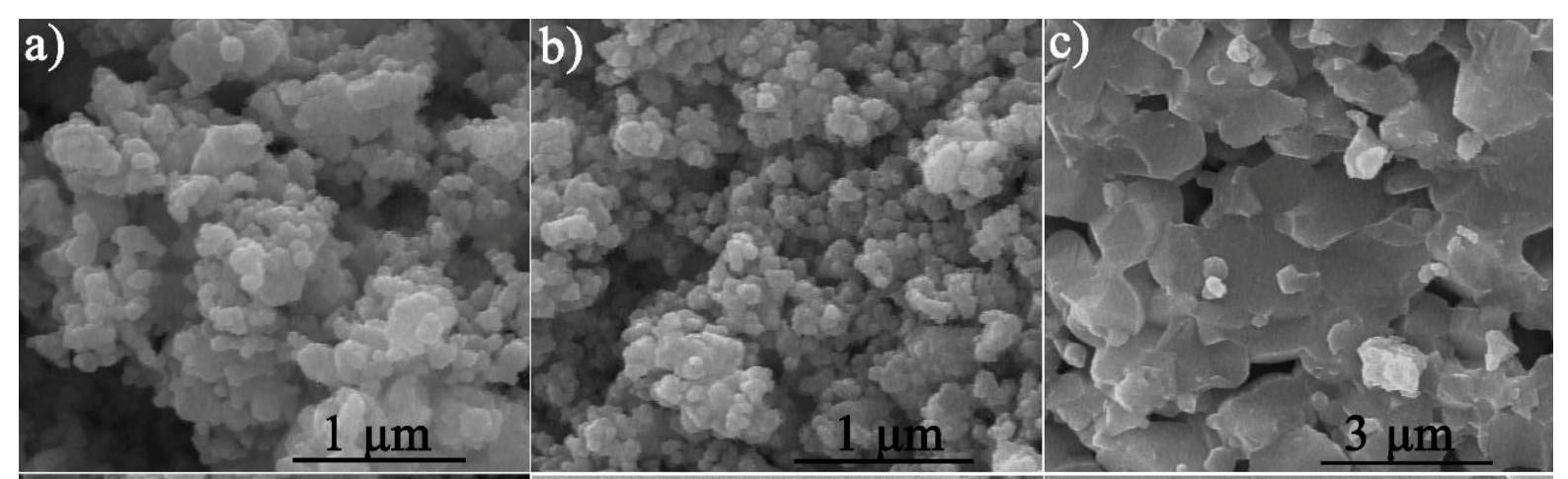

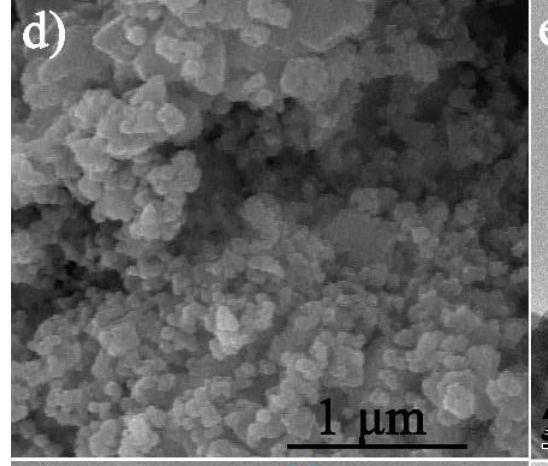

d)

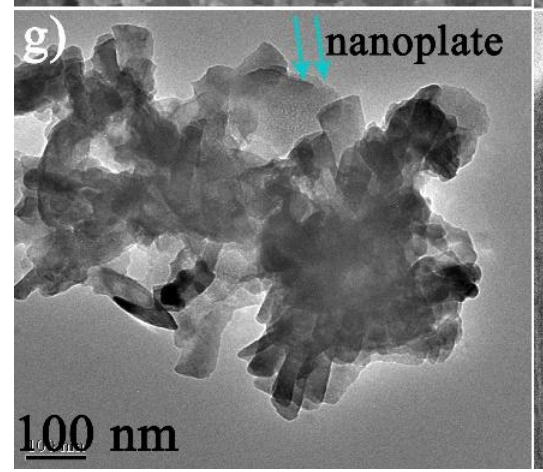

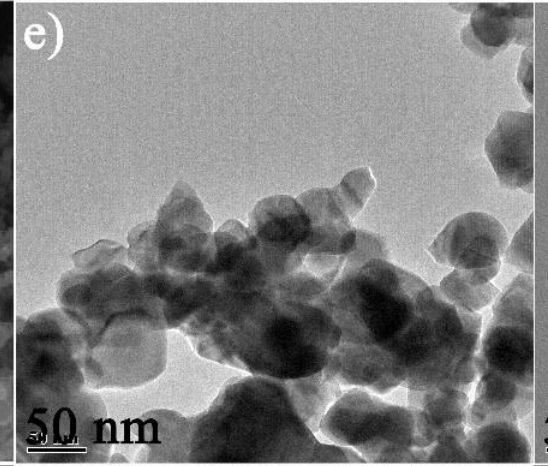

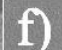

$50 \mathrm{~nm}$

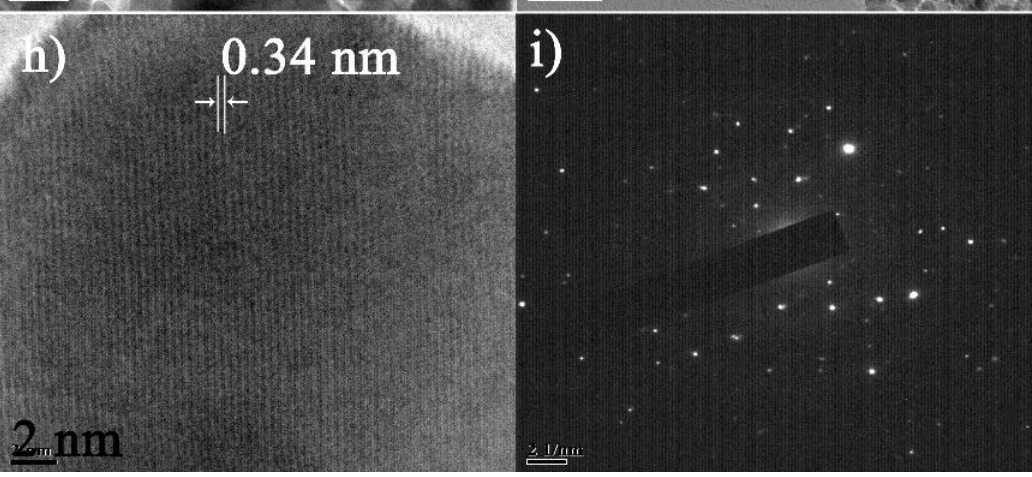

Fig 2. (a-d) SEM images of the samples No. 1-4, (e-g) TEM images of the samples No. 1-3, (h) HRTEM image and i) SAED pattern of $\mathrm{Zn}_{2} \mathrm{SnO}_{4}$ nanostructures (sample No. 2). 
Schematic diagram of formation of $\mathrm{Zn}_{2} \mathrm{SnO}_{4}$ product by different sugars is depicted in Fig $3 \mathrm{~g}$. The influence of photocatalytic activity of $\mathrm{Zn}_{2} \mathrm{SnO}_{4}$ nanoparticle prepared by sucrose as a capping agent were investigated by monitoring the degradation of eosin $\mathrm{Y}$ as water pollutant in an aqueous solution under UV light irradiation. The obtained results are shown in Fig. 3h. According to photocatalytic calculations, the eosin Y degradation was about $94 \%$ by $\mathrm{Zn}_{2} \mathrm{SnO}_{4}$ nanostructures after 120 min irradiation of $\mathrm{UV}$ light.

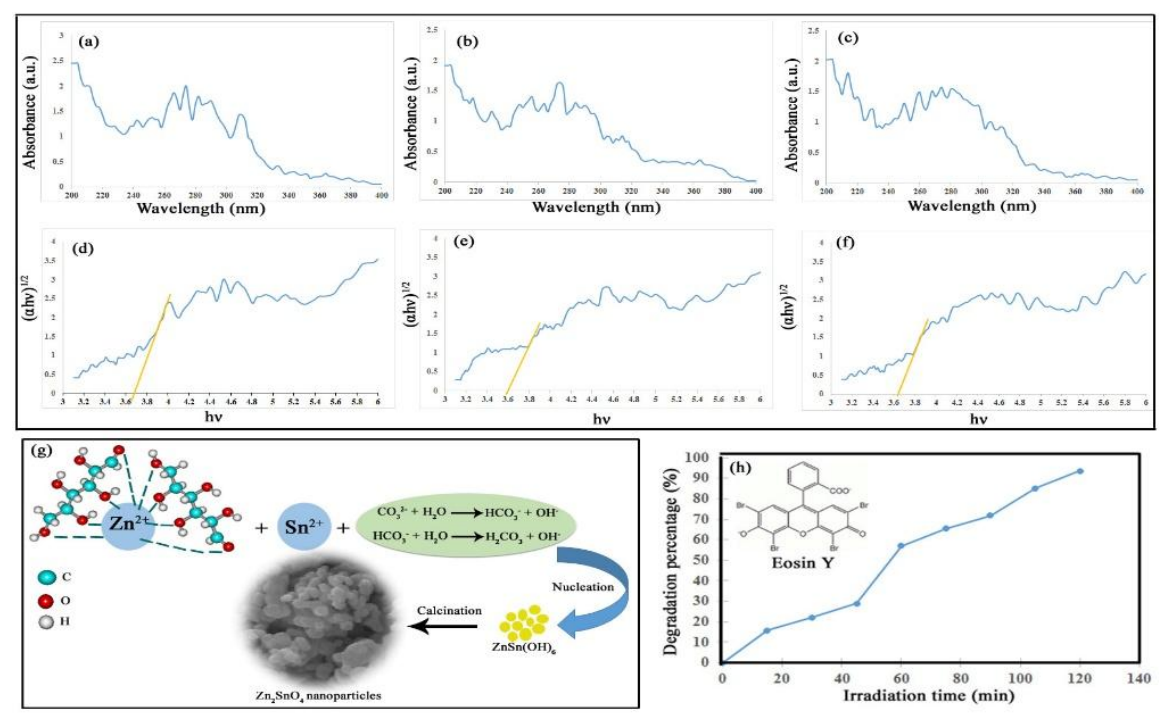

Fig. 3. (a-c) UV-Vis diffuse absorption spectra, (d-f) linear portion of the plots of (ahv) ${ }^{1 / 2}$ against hv of sample No.2-4, respectively, (g) Schematic diagram of formation of $\mathrm{Zn}_{2} \mathrm{SnO}_{4}$ nanostructures and (h) Photodecolorization eosin Y degradation of $\mathrm{Zn}_{2} \mathrm{SnO}_{4}$ nanostructures.

\section{Conclusion}

In summary, an eco-friendly, rapid and simple method to synthesize $\mathrm{Zn}_{2} \mathrm{SnO}_{4}$ nanostructures by carbohydrate sugars as a capping agent is developed. The effect of different carbohydrate sugars such as glucose, sucrose and starch on the size, morphology and optical properties of $\mathrm{Zn}_{2} \mathrm{SnO}_{4}$ nanostructures were investigated. The results demonstrated that applying the appropriate amount of sugars could be effective in particle size, morphology and optical properties control. The difference of band gap values of samples have been attributed to variations size and morphology of nanostructures.

\section{Acknowledgements}


Authors are grateful to the council of Iran National Science Foundation (91053846) and University of

Kashan for supporting this work by Grant No (159271/125).

\section{References}

[1] Wang YF, Li KN, Xu YF, Su CY, Kuangn DB. Nano energy 2013;2:1287-93.

[2] Foletto EL, Simões JM, Mazutti MA, Jahn SL, Muller EI, LSF Pereira, Moraes Flores EM. 2013;39:4569-74.

[3] Zhao Y, Huang Y, Wang Q, Wang K, Zong M, Wang L, Sun X. Ceramics Int 2014;140:2275-80.

[4] Jiang Y-Q, Chen X-X, Sun R, Xiong Z, Zheng L-S. Mater. Chem. Phys 2011;129:53-61.

[5] Wang K, Huangn Y, Huang H, Zhao Y, Qin X, Sun X, Wang Y, Ceram. Int 2014;40:8021-5.

[6] Babar AR, Kumbhar SB, Shinde SS, Moholkar AV, Kim JH, Rajpure KY, J. Alloys Compd 2011;509:7508-14.

[7] Hashemi T, Al-Allak HM, Illingsworth J, Brinkman AW, Woods J, J. Mater. Sci. Lett 1990;9:776-8.

[8] Wang L, Zhang X, Liao X, Yang W. Nanotechnology 2005;16:2928.

[9] Tharsika T, Haseeb ASMA, Akbar SA, Sabri MFM, Wong YH, J. Alloys Compd 2015; 618: 455-462.

[10] Tavakoli F, Salavati-Niasari M, Ghanbari D, Saberyan K, Hosseinpour-Mashkani SM. Mater. Res. Bull 2014;49:14-20.

[11] Mandizadeh S, Soofivand F, Salavati-Niasari M. Adv. Pow. Tech 2015; 26: 1348-1354.

[12] Ansari F, Bazarganipour M, Salavati-Niasari M. Mater. Sci. Semicond. Process 2016; 43: 34-40.

[13] Mandizadeh S, Bazarganipour M, Salavati-Niasari M. Ceram. Int 2014; 40: 15685-15691.

[14] Masjedi-Arani M, Salavati-Niasari M. Ultrason. Sonochem 2016; 29: 226-235.

[15] Tauc J, Grigorovici R, Vancu A. J. Phys. Status Solidi B 1966;15: 627-637.

[16] Hidalgo M, Aguilar M, Maicu M, Navio J, Colon G. J. Catal. Today 2007;129:50.

[17] Hossain F, Sheppard L, Nowotny J, Murch G. J. Phys. Chem. Solids 2008;69:1820-8. 